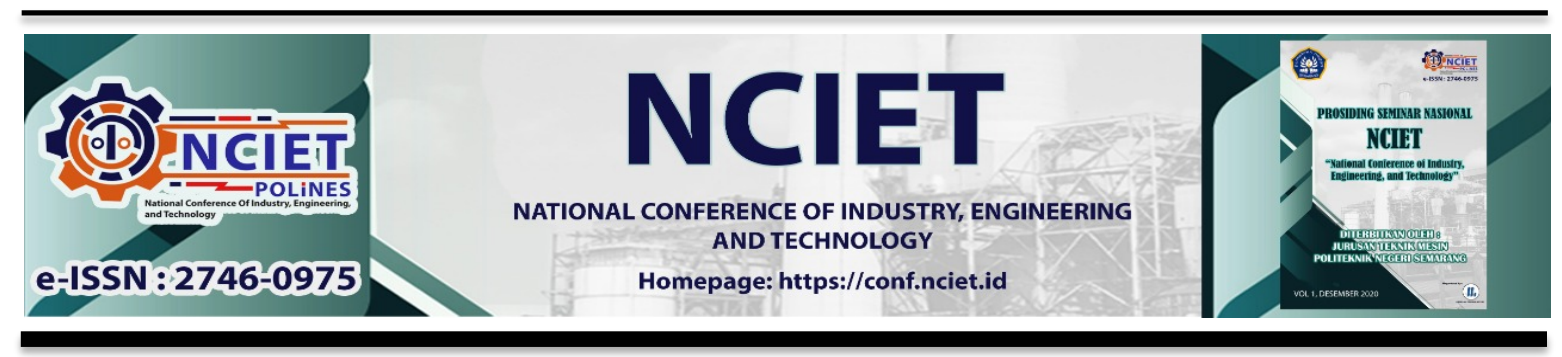

Prosiding Seminar Nasional NCIET Vol.1 (2020) B509-B517

$1^{\text {st }}$ National Conference of Industry, Engineering and Technology 2020,

Semarang, Indonesia.

\title{
OPTIMASI JARINGAN DISTRIBUSI LISTRIK DENGAN PEMASANGAN KAPASITOR PADA JARINGAN TEGANGAN MENENGAH 6.3 KV PT. SEMEN TONASA
}

\author{
Ismail*, Sarma Thaha, Agus Salim, Sofyan \\ Program Studi Teknik Elektro, Politeknik Negeri Ujung Pandang \\ Jl. Perintis Kemerdekaan KM. 10, Makassar, 90245 \\ *E-mail: fibriantiginting@gmail.com
}

\begin{abstract}
Abstrak
Kualitas daya dalam sistem tenaga merupakan hal yang sangat penting dan harus diperhatikan untuk menjaga stabilitas dan continuitas sistem tenaga listrik dalam suatu industri. Diantara permasalahan kualitas daya yang timbul salah satunya adalah penurunan nilai power factor yang menyebabkan konsumsi daya menjadi berlebih. Seperti pada industri industri besar pada umumnya. Pabrik Semen PT. Semen Tonasa juga memiliki permasalahan kualitas daya pada sistem kelistrikannya, disebabkan karna mempunyai banyak motor motor berkapasitas besar untuk proses produksinya. Pemasangan kapasitor pada sistem adalah salah satu cara untuk memecahkan permasalahan ini. Fungsi kapasitor adalah untuk pasokan daya reaktif sehingga kapasitor dapat memperbaiki faktor daya dan drop tegangan sehingga dapat memperkecil kerugian daya pada sistem. Didalam sistem kelistrikan PT. Semen Tonasa memiliki banyak variasi beban bus sehingga memasang kapasitor perlu mempertimbangkan optimalisasi lokasi penempatan dan kapasitas kapasitor. Pada tugas akhir ini akan mempelajari optimalisasi penempatan dan ukuran kapasitor bank pada sistem kelistrikan PT. Semen Tonasa untuk memperbaiki kualitas daya dengan menggunakan metode fast decouple Proses perbaikan ini disimulasikan menggunakan software ETAP 12.6. Dilakukan beberapa simulasi yakni simulasi aliran daya sebelum pemasangan kapasitor dan simulasi aliran daya setelah pemasangan kapasitor. Optimasi pemasangan kapasitor ini dilakukan sebanyak tiga kali dengan memilih kandidat bus yang berbeda-beda untuk menentukan letak, jumlah dan kapasitas kapasitor, serta analisis dari pemasangan kapasitor. Pemiliha beberapa bus yang mengalami jatuh tegangan sebagai kandidat bus hanya membutuhkan 342,8 Kvar.
\end{abstract}

Kata kunci: Power Factor, Kapasitor Bank, Electrical Transient Analyser Program (ETAP)

\section{PENDAHULUAN}

Dalam penyaluran energi listrik ada beberapa masalah yang dihadapi antara lain jatuh tegangan, faktor daya yang rendah dan rugi-rugi daya. Beban pada jaringan distribusi bisa berupa beban kapasitif maupun induktif, namun pada umumnya merupakan beban induktif. Apabila beban reaktif induktif semakin tinggi maka akan berakibat memperbesar jatuh tegangan, memperbesar rugi-rugi daya, menurunkan faktor daya dan menurunkan kapasitas 
penyaluran daya. Untuk mengurangi beban daya reaktif induktif diperlukan sumber daya reaktif kapasitif, salah satu diantaranya adalah dengan kapasitor yang dipasang secara paralel pada penghantar penyulang distribusi primer radial. Pemasangan kapasitor shunt tersebut menyebabkan arus yang mengalir pada penghantar menjadi lebih kecil, sehingga akan mengurangi besarnya rugi-rugi daya dan jatuh tegangan.

Umumnya penyaluran akan daya listrik digunakan melayani beban-beban seperti: motor-motor listrik, transformator, lampu TL dan peralatan listrik lainnya dimana bebanbeban tersebut mengandung gulungan-gulungan kawat (induktor). Induktor merupakan komponen yang menyerap daya listrik untuk keperluan magnetisasi dan daya lisrik tersebut disebut daya reaktif. Suatu beban dikatakan induktif apabila beban tersebut membutuhkan daya reaktif dan disebut kapasitif apabila menghasilkan daya reaktif. Bertambahnya beban yang bersifat induktif membutuhkan daya reaktif yang sangat besar sehingga sumber (pembangkit listrik) harus mensuplai daya yang lebih besar. Keadaan seperti ini dapat menyebabkan jatuh tegangan, arus pada jaringan bertambah dan faktor daya rendah pada daerah dekat beban.

Berdasarkan permasalahan tersebut, beberapa cara yang efektif dan efisien yang dapat dipilih untuk mendapatkan nilai yang optimum pada sistem tenaga listrik yaitu diantaranya adalah optimasi daya reaktif dengan cara membangun generator baru, pengaturan tap trafo, instalasi auto voltage regulator, dan instalasi kapasitor.

Dari ketiga metode di atas menunjukan tidak efektifnya infrastruktur maupun jika dilihat dari segi biaya. Adapun metode yang paling tepat dan memungkinkan untuk bekerja lebih efektif yaitu dengan menggunakan kapasitor bank (pembangkit daya reaktif) baik penggunaan secara paralel maupun seri. Kapasitor sendiri merupakan suatu komponen elektronik yang dibangun dari sejumlah kapasitor yang berfungsi untuk memperbaiki faktor daya, tetapi pemakaian kapasitor ini haruslah dicocokkan dengan kebutuhan yang ada dan tidak bisa sembarang pasang dengan berbagai macam posisi. Oleh karena itu, perlu dilakukan studi perencanaan dalam melakukan analisis pemasangan kapasitor bank untuk menanggulangi beban induktif yang ada.

Rumusan Masalah

Berdasarkan latar belakang yang dikemukakan, maka dapat dirumuskan permasalahan seperti berikut : 
1. Bagaiman pengaruh pemasangan Kapasitor terhadap faktor daya untuk mengoptimalkan jaringan distribusi ?

2. Bagaimana stabilitas tegangan pada sistem distribusi setelah pemasangan kapasitor ?

Tujuan Penelitian

Tujuan dari penelitian ini adalah :

1. mengetahui pengaruh pemasangan Kapasitor terhadap faktor daya untuk mengoptimalkan jaringan distribusi

2. mengetahui stabilitas tegangan pada sistem distribusi setelah pemasangan kapasitor bank.

Manfaat Penelitian

1. Memberikan informasi tentang nilai faktor daya yang dihasilkn dan pengaruh dari pemasangan kapasitor bank terhadap beban listrik yang digunakan

3. Memberikan informasi bagaimana Menstabilkan tegangan yang mengalami undervoltage/overvolteg

\section{METODE PENELITIAN}

Bagaimana cara optimasi jaringan distribusi di PT. Semen Tonasa dengan menggunakan kapasitor Bank. Data yang digunakan pada penelitian ini adalah data sekunder. Adapun langkah-langkah metode penelitian ini, yaitu :

1. Studi literature dengan mempelajari berbagai sumber referensi tugas akhir atau teori (buku dan internet) yang berkaitan dengan masalah yang dibahas dalam penelitian ini.

2. Mengumpulkan data-data mengenai single line diagram pada sistem tenaga listrik

3. Pemodelan sistem sistem tenaga listrik dalam bentuk single line diagram menggunakan Software ETAP 16.0.0.

bagaimana cara optimasi jaringan distribusi di PT. Semen Tonasa dengan menggunakan kapasitor. Data yang digunakan pada penelitian ini adalah data sekunder yang diperoleh langsung dari PT. Semen Tonasa 


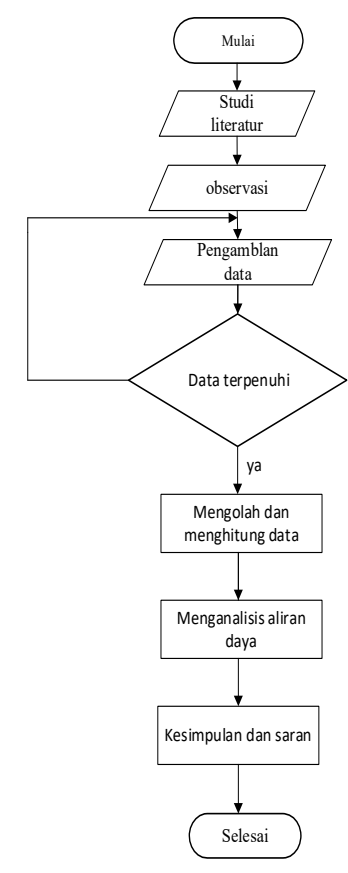

Gambar 1 . flowcart prosedur pengelolah data

\section{Mengolah Data}

Dalam penelitian ini metode analisis data yang digunakan adalah analisis deskriptif dengan perhitungan berdasarkan teori dan menggunakan software ETAP 16.0.0, yaitu untuk mengetahui Optimasi Jarigan Distribusi yang terjadi pada jaringan tegangan rendah PT. Semen Tonasa V pada gardu distribusi. Metode perhitungan aliran daya menggunakan metode fast decoup

\section{HASIL DAN PEMBAHASAN}

\section{Hasil simulasi sistem kelistrikan PT. Semen Tonasa sebelum penempatan kapasitor}

Berikut hasil dari simulasi aliran daya pada sistem kelistrikan PT. Semen Tonasa sebelum penenmpatan kapasitor dapat dilihat pada gambar di bawah ini Menggunakan ETAP Power Station 16.0.0. Bus yang berwarna merah maupun merah muda menandakan bus tersebut mengalami jatuh tegangan. 


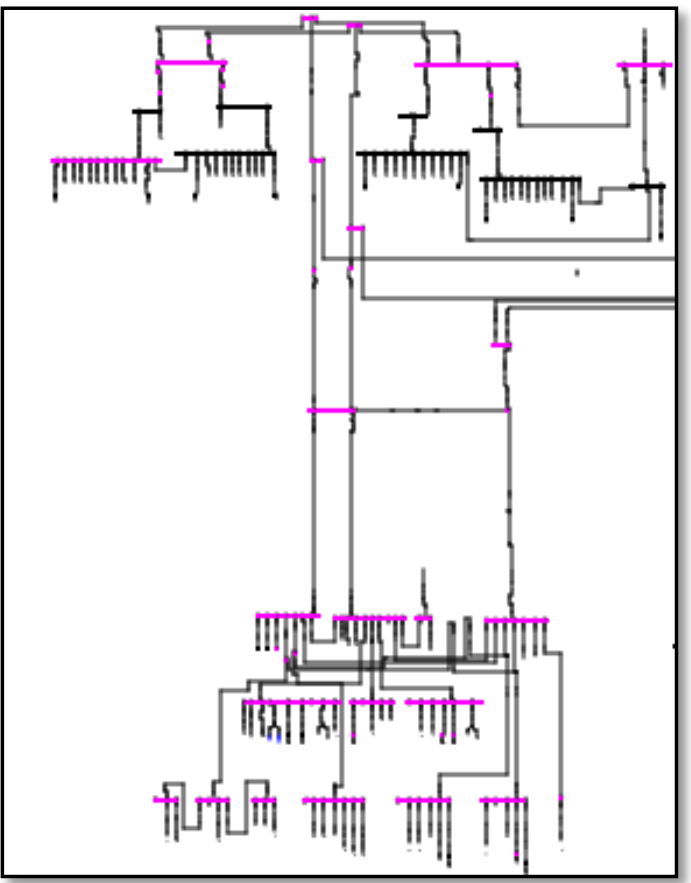

Gambar 2. Hasil Simulasi system kelistrikan PT. Semen Tonasa V pada software ETAP Power Station 16.0.0 sebelum pemempatan kapasitor bank

Tabel 1. hasil simulasi aliran daya sebelum pemasangan kapasitor Menggunakan ETAP Power Station 16.0.0

\begin{tabular}{|c|c|c|c|c|c|}
\hline Bus ID & $\begin{array}{l}\text { Nominal } \\
\mathrm{kV}\end{array}$ & Voltage & $\begin{array}{l}\text { MW } \\
\text { Loading }\end{array}$ & $\begin{array}{l}\text { Mvar } \\
\text { Loading }\end{array}$ & $\begin{array}{l}\text { Amp } \\
\text { Loading }\end{array}$ \\
\hline $\begin{array}{ll}580 & \text { TB } \\
02 & \end{array}$ & 70 & 70.65 & 9.999 & 6.541 & 97.64 \\
\hline 580TB01 & 70 & 70.65 & 20.878 & 14.534 & 207.9 \\
\hline 581SS51 & 6.3 & 6.464 & 9.961 & 6.672 & 1071 \\
\hline $581 \mathrm{SS} 52$ & 6,3 & 6.477 & 7.753 & 6.485 & 901 \\
\hline $581 \mathrm{SS} 53$ & 6.3 & 6.443 & 9.77 & 4.487 & 963.4 \\
\hline $\begin{array}{ll}582 & \text { ER } \\
51 & \end{array}$ & 6.3 & 6.432 & 1.387 & 0.856 & 146.3 \\
\hline $\begin{array}{ll}582 & \text { ER } \\
52 & \end{array}$ & 6.3 & 6.435 & 3.157 & 2.462 & 359.2 \\
\hline
\end{tabular}




\begin{tabular}{|ll|l|l|l|l|l|}
\hline Bus ID & $\begin{array}{l}\text { Nominal } \\
\mathrm{kV}\end{array}$ & Voltage & $\begin{array}{l}\text { MW } \\
\text { Loading }\end{array}$ & $\begin{array}{l}\text { Mvar } \\
\text { Loading }\end{array}$ & $\begin{array}{l}\text { Amp } \\
\text { Loading }\end{array}$ \\
\hline $\begin{array}{l}582 \\
53\end{array}$ & ER & 6.3 & 6.348 & 0.888 & 0.928 & 116.8 \\
\hline $\begin{array}{l}582 \\
54\end{array}$ & ER & 6.3 & 6.439 & 6.747 & 4.22 & 713.6 \\
\hline $\begin{array}{l}582 \\
57\end{array}$ & ER & 6.3 & 6.457 & 1.217 & 0.721 & 126.4 \\
\hline
\end{tabular}

\section{Hasil simulasi sistem kelistrikan PT. Semen Tonasa sebelum penempatan kapasitor}

Berikut hasil dari simulasi aliran daya pada sistem kelistrikan PT. Semen Tonasa setelah penenmpatan kapasitor dapat dilihat pada gambar di bawah ini Menggunakan ETAP Power Station 16.0.0. dapat dilihat bahwa terjadi pengurangan jatuh tegangan, dengan kata lain nilai tegangan pada setiap semua bus telah berada pada nilai yang sesuai dengan standar yang ada.

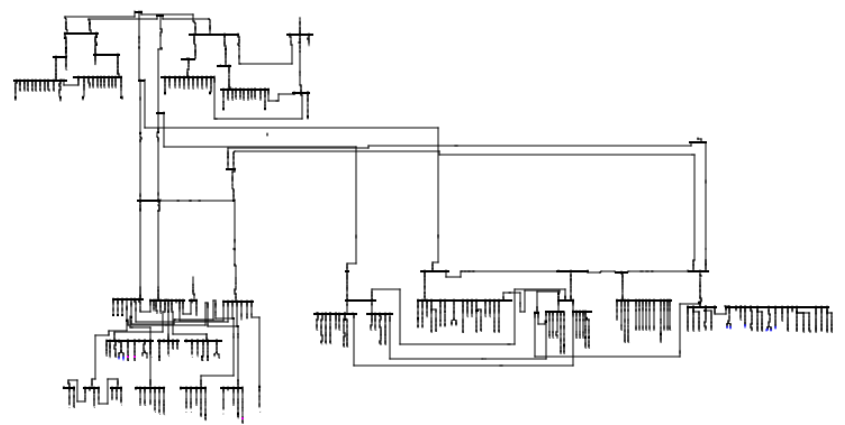

Gambar 3. Hasil Simulasi system kelistrikan PT. Semen Tonasa V pada software ETAP Power Station 16.0.0 sebelum pemempatan kapasitor bank

Tabel 2. hasil simulasi aliran daya setelah pemasangan kapasitor Menggunakan ETAP Power Station 16.0.0

\begin{tabular}{|l|l|l|l|l|l|}
\hline Bus ID & $\begin{array}{l}\text { Nominal } \\
\mathrm{kV}\end{array}$ & Voltage & $\begin{array}{l}\text { MW } \\
\text { Loading }\end{array}$ & $\begin{array}{l}\text { Mvar } \\
\text { Loading }\end{array}$ & $\begin{array}{l}\text { Amp } \\
\text { Loading }\end{array}$ \\
\hline $\begin{array}{l}580 \mathrm{~TB} \\
02\end{array}$ & 70 & 68,45 & 9,999 & 6,331 & 98,65 \\
\hline $580 \mathrm{~TB} 01$ & 70 & 6,334 & 32,02 & 33,772 & 387,9 \\
\hline
\end{tabular}




\begin{tabular}{|c|c|c|c|c|c|}
\hline Bus ID & $\begin{array}{l}\text { Nominal } \\
\mathrm{kV}\end{array}$ & Voltage & $\begin{array}{l}\text { MW } \\
\text { Loading }\end{array}$ & $\begin{array}{l}\text { Mvar } \\
\text { Loading }\end{array}$ & $\begin{array}{l}\text { Amp } \\
\text { Loading }\end{array}$ \\
\hline 581SS51 & 6,3 & 6,269 & 9,932 & 5,159 & 1015 \\
\hline $581 \mathrm{SS} 52$ & 6,3 & 6,235 & 7,73 & 8,93 & 1064 \\
\hline $581 \mathrm{SS} 53$ & 6,3 & 6,32 & 9,754 & 4,18 & 969,7 \\
\hline $\begin{array}{ll}582 & \mathrm{ER} \\
51 & \end{array}$ & 6,3 & 6,326 & 1,383 & 0,853 & 147,9 \\
\hline $\begin{array}{ll}582 & \text { ER } \\
52 & \end{array}$ & 6,3 & 6,204 & 3,137 & 1,523 & 317,3 \\
\hline $\begin{array}{ll}582 & \text { ER } \\
53 & \end{array}$ & 6,3 & 6,309 & 0,884 & 1,493 & 159,4 \\
\hline $\begin{array}{ll}582 & \text { ER } \\
54 & \end{array}$ & 6,3 & 6,249 & 6,742 & 4,217 & 724,2 \\
\hline $\begin{array}{ll}582 & \text { ER } \\
57 & \end{array}$ & 6,3 & 6,224 & 1,213 & 0,718 & 127,4 \\
\hline
\end{tabular}

Berdasakan tabel di atas, setelah adanya penambahan kapasitor, dapat dilihat bahwa terjadi pengurangan jatuh tegangan, dengan kata lain nilai tegangan pada setiap semua bus telah berada pada nilai yang sesuai dengan standar yang ada.

\section{Pembahasan}

Untuk perbaikan jaringan distribusi dalam menstabilkan kinerja motor-motor yang mengalami factor daya bekerja dibawah standar yang diinginkan oleh PT.Semen Tonasa, maka di butuhkan persamaan (2.7) pada pembahasab BAB II.

$$
\begin{aligned}
& \text { Daya Semu } \left.=\sqrt{\mathrm{kVAR}^{2}+\mathrm{kW}^{2}}=\frac{\mathrm{kW}}{\operatorname{Cos} \varphi} \quad\right) \\
& \mathrm{Q}_{\mathrm{b}}=\mathrm{P} \operatorname{Tan} \varphi_{1} \\
& \mathrm{Q}_{\mathrm{t}}=\mathrm{P} \operatorname{Tan} \varphi_{2}
\end{aligned}
$$

Sehingga :

$$
\mathrm{Q}_{\mathrm{c}}=\mathrm{Q}_{\mathrm{b}}-\mathrm{Q}_{\mathrm{C}}
$$

\section{CRO1MO1}

\section{- Q1 Keadaan daya reaktif awal}


$\mathrm{S}=870$

P1 $=870$ Kva.0,39

$\mathrm{P} 1=339,9 \mathrm{MW}$

$=\sqrt{\mathrm{S}} 2-\mathrm{P} 1$

$=\sqrt{870^{2}}-339,3$

$=801,1 \mathrm{kVAR}$

\section{Q2 Keadaan daya reaktif di harapkan}

P1 $=\sqrt{ } 870$ Kva.0,85

$\mathrm{P} 1=458,3 \mathrm{MW}$

$=\sqrt{\mathrm{S}} 2-\mathrm{P} 2$

$=\sqrt{870^{2}-739,5^{2}}$

$=458,3 \mathrm{kVAR}$

$\mathrm{Q}_{\mathrm{c}}=\mathrm{Q}_{\mathrm{b}}-\mathrm{Q}_{\mathrm{C}}$

$\mathrm{Q}_{\mathrm{c}}=801,1-458,3$

$\mathrm{Q}_{\mathrm{C}}=342,8 \mathrm{Kvar}$

\section{Analisis Hasil Simulasi}

Berdasarkan hasil simulasi analisis aliran daya sebelum pemasangan kapasitor pada sistem kelistrikan PT Semen Tonasa Sektor Tonasa V, terlihat bahwa tegangan sistem memiliki kualitas yang kurang baik, karena terdapat jatuh tegangan, yang nilainya berada di bawah standar 0.9 p.u

Adanya jatuh tegangan pada sistem ini disebabkan karena banyaknya beban-beban induktif yang digunakan pada PT Semen Tonasa, sehingga permintaan suplai daya reaktif meningkat. Ketika tidak terdapat supplai daya reaktif di sekitar beban, generator akan menjadi satusatunya penyuplai daya reaktif sehingga akan menyebabkan terjadinya penurunan kualitas tegangan. Oleh karena itu, sistem dianggap tidak stabil dan diperlukan penambahan kompensator kVAr berupa kapasitor bank.

Penambahan kapasitor bank ini memerlukan analisis Optimal Capacitor Placement guna menentukan lokasi penempatan kapasitor yang paling optimal, dan juga menentukan kapasitas kapasitor yang harus digunakan serta menentukan jumlah kapasitor yang harus dipasang di tiap bus terpilih, guna memperbaiki kualitas tegangan pada sistem. 
Berdasarkan hasil simulasi di atas, dapat dilihat bahwa simulasi room 582 ER 51 membutuhkan injeksi daya reaktif sebesar 725 kVAr, room 582 ER 52 638,84 Kvar, room 582 ER 53 sebesar 63,70 kVAr, untuk meningkatkan kualitas tegangan yang ada pada sistem. Hal ini dikarenakan kandidat bus yang digunakan adalah hanya beberapa dari bus yang mengalami jatuh tegangan, sehingga pemasangan kapasitor hanya dilakukan pada bus-bus tersebut. Sehingga daya reaktif yang dihasilkan oleh kapasitor akan langsung mengalir ke beban induktif, sehingga mampu meningkatkan kualitas tegangan.

\section{KESIMPULAN}

Berdasarkan hasil simulasi yang telah dilakukan dengan menggunakan software ETAP 12.6 maka dapat diambil kesimpulan sebagai berikut:

1. Untuk memperbaiki kualitas tegangan pada sistem kelistrikan PT Semen Tonasa Sektor Tonasa V, maka diperlukan 1777,58 kVAr, sebanyak 3 buah kapasitor yang dipasang pada 7 bus yang berbeda. 4 (empat) buah kapasitor 725,5 kVAr dipasang pada bus 582 ER 51 168,5 kVAr di pasang pada buss 582 ER 533 (tiga) buah.

2. Hasil simulasi menggunakan software ETAP 16.0.0 dimana factor daya yang di hasilkan mendekati standar factor daya yang di tentukan PT.Semen Tonasa, namun perlu perbaikan agar kerja beban motor listrik maksim

\section{DAFTAR PUSTAKA}

Ahmad Ardiyansyah, Analisis Keandalan Sistem Jaringan Distribusi Udara 20 kV, 2010. Al Qahfi, Andi Sultan Alauddin, dan Rizqi Amalia Burhan. 2016. "Studi Pengaruh Kapasitor Shunt terhadap Susut Transmisi Sistem Interkoneksi SULSELRABAR". Laporan Tugas Akhir. Makassar : Politeknik Negeri Ujung Pandang.

AS Pabla, Sistem Distribusi Daya Listrik, PT. Anem Kosong Anem, 1973..

Dr. Artono Arismunandar, Buku Pegangan Teknik Tenaga Listrik Jilid III : Gardu Induk, Penerbit Erlangga, 1981.Haris Muhammad, Analisis Rugi Daya Di Penyulang Unhas PT. PLN (Persero) Rayon Makassar Timur.

Eko Wijanarko (L2F 002 576) Optimasi Penempatan Kapasitor Shunt Untuk Perbaikan Daya Reaktif Pada Penyulang Distribusi Primer Radial Dengan Algoritma Genetik

Nolki Jonal Hontong,Maickel Tuegeh ST. MT., Lily.S. Patras ST. MT. Analisa Rugi - Rugi Daya Pada Jaringa Distribusi Di PT. PLN Palu

Slamet Suripto, Buku Ajar Sistem Tenaga listrik

Suhadi dkk, Teknik Tenaga Listrik Jilid I,Jakarta, Direktorat Pembinaan Sekolah Menengah Kejuruan, 2008. 